\title{
SNI ON LINE DAN DAMPAKNYA TERHADAP PERMINTAAN STANDAR
}

\author{
Tisyo Haryono
}

\begin{abstract}
Abstrak
Sebagai dokumen penting yang dirumuskan melalui konsensus secara nasional, SNI perlu dikelola dan disajikan dengan baik agar dapat digunakan oleh masyarakat luas. Penyajian SNI dapat dilakukan melalui berbagai cara antara lain secara on line di website untuk dapat diakses melalui internet sehingga masyarakat memperoleh kemudahan tanpa hambatan waktu dan isolasi geografis. Untuk mengetahui sejauhmana pemanfaatan layanan SNI online oleh masyarakat, telah dilakukan analisis terhadap data penggunaannya selama tahun 2004. Hasil analisis menunjukan bahwa layanan SNI on line mendapat respon positif dari masyarakat dan SNI on line juga ternyata tidak mengakibatkan penurunan jumlah permintaan $\mathrm{SNI}$ di perpustakaan bahkan sebaliknya mampu meningkatkannya. SNI on line diketahui telah mampu mendorong minat masyarakat untuk mengetahui lebih jauh SNI yang ada. Hasil analisis mengandung implikasi bahwa kebijakan BSN untuk menyelenggarakan layanan SNI on line sebagai sarana penyebarluasan SNI sudah tepat dan perlu dilanjutkan sedangkan dalam pelaksanaaannya perlu terus disempurnakan.
\end{abstract}

Kata kunci: standar, SNI on line, permintaan standar

\section{Abstract}

As a normative document generated through a national consensus, Indonesia National Standard (SNI) is to be processed and disseminated properly in order to serve public needs. Presentation of SNI could be in different forms, among others, is presenting it online through BSN website which is accessible publicly with no time and geographic isolation constraints. To see the actual use of SNI online by the potential users since the beginning of its establishment in 2004, an analysis was conducted to see whether it is or not extensively utilized by stakeholders. The result was reported that SNI online could not only get positive public responses, but increase the total request of standards in BSN library as well. SNI online, in addition, could motivate people to get more access to standards. The implication of the analysis is that BSN policy on SNI online as a means of disseminating standards, is to be continued whit some improvements needed.

Keywords: standard, SNI on line, standard request

\section{PENDAhUluan}

Standar adalah dokumen yang berisi ketentuan teknis dari sebuah produk, metode, proses atau sistem, yang dirumuskan secara konsensus, dan ditetapkan oleh instansi yang berwenang. Standar disusun dengan tujuan untuk menciptakan keteraturan optimum dalam konteks tertentu menuju keamanan dan keselamatan umat manusia dan lingkungannya. Standar merupakan produk inti (core product) dari kegiatan standardisasi, yakni kegiatan yang dilakukan oleh badan standardisasi, baik secara nasional maupun internasional. SNI on line yang dimaksud dalam tulisan ini adalah Standar Nasional Indonesia yang berupa dokumen elektronik lengkap (fulltext) dan disajikan pada website BSN www.bsn.go.id untuk digunakan secara luas oleh masyarakat.

Pada awal tahun 2005, Indonesia memiliki Standar Nasional Indonesia (SNI) sebanyak 6.565 judul yang terdiri dari berbagai bidang. Jumlah yang paling besar adalah untuk bidang perindustrian, pertanian/pangan, kesehatan, kelistrikan/elektroteknik dan konstruksi. Standar Nasional Indonesia disusun melalui proses perumusan yang panjang dari mulai penyusunan rancangan oleh Panitia Teknis (Pantek) Perumusan Standar yang berada di bawah koordinasi Instansi Teknis (Departemen/LPND) tekait, rapat konsensus para "stake holder" hingga ditetapkan menjadi SNI oleh Kepala Badan Standardisasi Nasional (BSN). Untuk membangun kepercayaan masyarakat terhadap SNI, maka pada akhir-akhir ini proses perumusan SNI terus disempurnakan terutama dalam mekanisme konsensus melalui e-balloting untuk menjamin transparansi dan fairness dari setiap SNI yang dirumuskan.

\section{AKSES TERHADAP SNI}

SNI disusun oleh Panitia Teknis yang dikoordinasikan oleh Instansi Teknis dan ditetapkan oleh Badan Standardisasi Nasional. Penyusunan SNI pada umumnya menggunakan anggaran pemerintah (APBN) melalui anggaran yang dialokasikan kepada Instansi teknis. Oleh karena itu SNI adalah public domain artinya bahwa masyarakat memiliki hak untuk akses 
terhadap SNI. Kewajiban BSN sebagai lembaga pemerintah yang bertanggungjawab di bidang pengembangan dan pembinaan standardisasi antara lain adalah menyebarluaskan SNI tersebut kepada masyarakat melalui berbagai upaya. SNI on line merupakan salah satu diantara upaya yang sedang dikembangkan BSN pada saat ini.

Di masa yang lalu, pada saat anggaran pemerintah masih memadai, penyebaran SNI dilakukan melalui pencetakan dalam jumlah besar dan disebarkan secara luas berdasarkan mailing list yang ada. BSN telah melakukannya beberapa tahun dan ternyata tidak mungkin untuk dilanjutkan. Keterbatasan anggaran pemerintah akhir-akhir ini, menuntut BSN hanya menggandakan secara terbatas SNI yang ditetapkan. SNI pada saat ini tidak lagi dicetak dalam jumlah banyak. Namun informasi tentang keberadaan SNI terbaru masih tetap disebarkan secara luas baik melalui publikasi tercetak maupun secara elektronik.

\section{SNI ON LINE}

Keterbatasan kemampuan mencetak SNI selama ini menjadi tantangan dan telah mendorong BSN mencari alternatif penyebarluasan SNI kepada masyarakat. Sejalan dengan adanya Instruksi Presiden No.3 Tahun 2000, tentang Kebijakan Pemerintah di bidang e-government, yang pada intinya adalah mendorong instansi pemerintah agar membangun layanan publik yang prima, maka BSN telah membangun layanan SNI on line yang mulai di uji coba pada pertengahan tahun 2003. Layanan ini bertujuan untuk perluasan dan kemudahan akses masyarakat terhadap SNI.
SNI on line menyajikan dokumen SNI secara lengkap hasil penetapan satu tahun terakhir. Dalam kurun waktu satu tahun, standar tersebut dapat dibaca, di print dan di download oleh pengguna secara cuma-cuma tanpa harus meminta izin kepada penerbit. Layanan seperti ini ternyata dapat diketahui dan digunakan oleh masyarakat melalui akses terhadap website BSN.

Untuk mengetahui sejauh mana masyarakat mengakses website BSN, maka BSN telah mencoba menganalisa data tentang jumlah hit pada website BSN. Satu hit diasumsikan sebagai akses yang berhasil pada salah satu file di website BSN oleh satu komputer user yang dilakukan pada satu hari. Dengan demikian, user yang sama walaupun mengakses beberapa file pada satu hari tetap dianggap sebagai satu hit. Ini untuk menghindari bias karena dalam satu hari suatu komputer user bisa mengakses hingga ratusan kali, sehingga tanpa asumsi tersebut hal itu bisa dianggap adanya hit yang jumlahnya besar.

Asumsi lain yang digunakan adalah user diwakili oleh satu IP (Internet Protocol) address. Beberapa user yang memakai komputer yang sama (dengan IP address yang sama) dianggap sebagai satu komputer user. Asumsi ini dibuat karena tidak mungkin mengetahui user siapa saja yang memakai suatu komputer dengan IP address yang sama.

Berdasarkan data log website BSN, sejak tanggal 1 Januari hingga 31 Desember 2004, didapatkan jumlah hit sebesar 126.640 yang berasal dari 45.268 komputer user. Namun pengamatan yang lebih teliti menunjukkan bahwa sebagian besar komputer user tersebut melakukan akses hanya sekali. Untuk mendapatkan kesimpulan yang lebih akurat, maka data tersebut dibagi menjadi beberapa segmen sebagai berikut :

Tabel 1 Akses Pengguna terhadap Website BSN

\begin{tabular}{|l|r|r|}
\hline \multicolumn{1}{|c|}{ Range Jumlah Hit } & Jumlah Komputer User & Jumlah Hit \\
\hline $1-5$ & 42.175 & 56.532 \\
$6-10$ & 1.381 & 10.379 \\
$11-20$ & 817 & 11.893 \\
$21-30$ & 312 & 7.785 \\
$31-50$ & 264 & 10.518 \\
$51-100$ & 228 & 15.970 \\
Lebih dari 100 & 91 & 13.563 \\
\hline
\end{tabular}


Dengan menganggap user potensial adalah yang mengakses lebih dari 5 kali, maka diperoleh data jumlah hit sebesar 70.108 kali dari 3.093 komputer user.
BSN mengujicoba pengembangan SNI online sejak bulan Juni 2003. Jumlah akses SNI fulltext yang dilakukan pengguna website pada tahun 2004 dapat dilihat dalam grafik berikut :

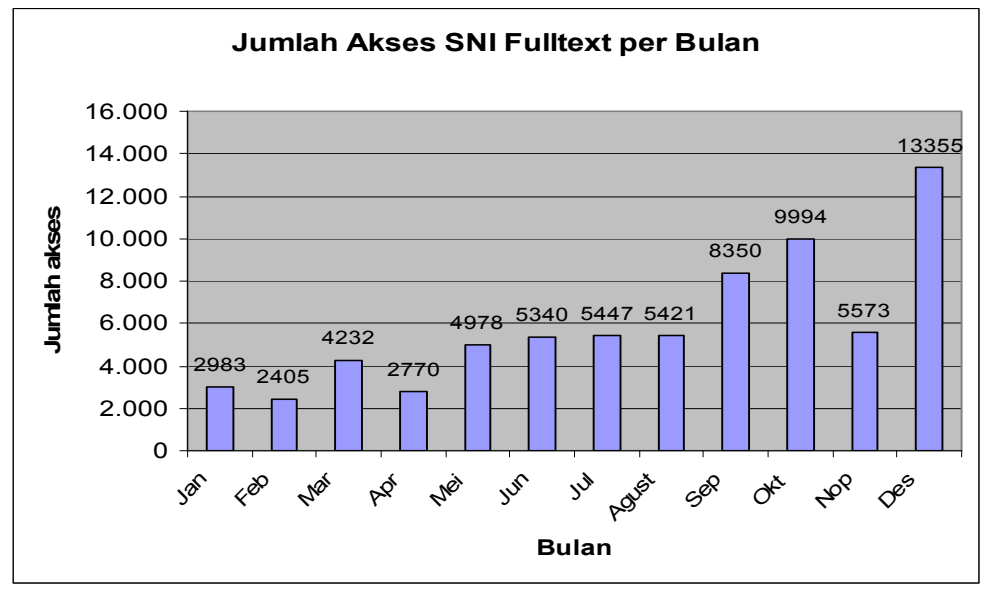

Gambar 1 Jumlah Akses SNI Fulltext per Bulan (Sumber: Laporan Tahunan Pusido, 2004)

Sedangkan untuk $10 \mathrm{SNI}$ terbanyak yang diakses adalah sebagai berikut :

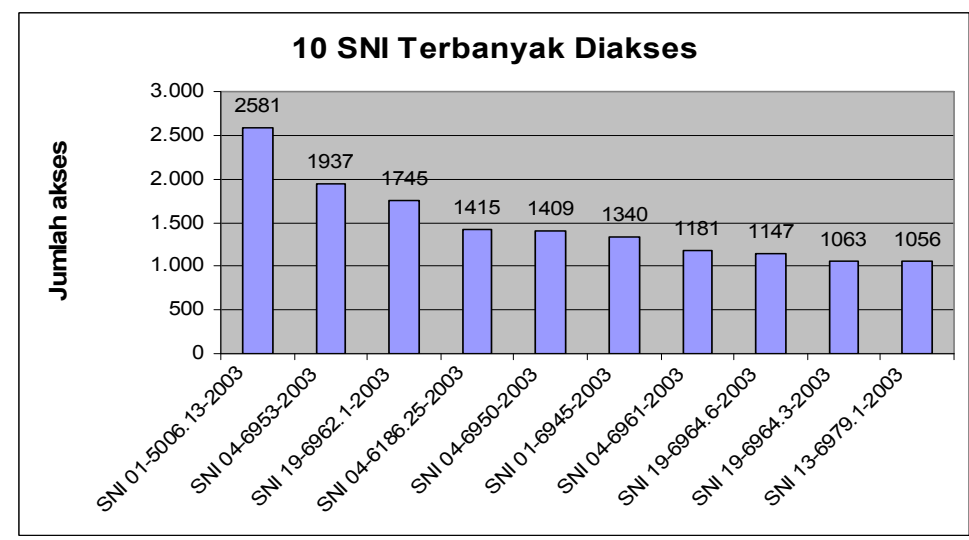

Gambar 2 Sepuluh Besar SNI yang Diakses (Sumber: Laporan Tahunan Pusido, 2004)

Dari grafik di atas diketahui bahwa pengguna SNI online melalui situs web bsn.go.id selama tahun 2004 sangat bervariasi dari bulan ke bulan. Penggunaan tertinggi terjadi pada bulan Desember 2004 sebanyak 13.355 kali sedangkan penggunaan terendah terjadi pada bulan Februari sebanyak 2.405 kali.

\section{DAMPAK SNI ON LINE TERHADAP PERMINTAAN STANDAR}

Layanan SNI on line diselenggarakan untuk tujuan perluasan dan kemudahan akses masyarakat terhadap SNI karena akses di masa yang lalu belum seperti yang diharapkan. Dugaan semula bahwa karena masyarakat dapat akses langsung ke SNI fulltext, khususnya hasil penetapan satu tahun terakhir, maka permintaan
SNI ke perpustakaan akan menurun karena sebagian kebutuhan mereka sudah terpenuhi melalui layanan $\mathrm{SNI}$ on line. Namun pada kenyataannya terjadi sebaliknya.

Peningkatan jumlah permintaan SNI di perpustakaan BSN besar kemungkinan berkaitan dengan penyelenggaraan layanan SNI on line. Data tersebut menunjukan bahwa keberadaan $\mathrm{SNI}$ on line bukan sebagai kompetitor melainkan komplementer terhadap layanan yang ada. Layanan SNI on line telah berhasil mendorong masyarakat untuk mengetahui lebih banyak SNI yang ada di website. SNI on line juga telah mampu mendorong peningkatan layanan enquiry, yaitu layanan yang disediakan BSN untuk menjawab berbagai pertanyaan masyarakat sekitar masalah standardisasi. 
Tabel 2 Permintaan Standar di Perpustakaan BSN Tahun 2003 dan 2004

\begin{tabular}{|c|r|r|r|r|}
\hline $\begin{array}{c}\text { Jenis } \\
\text { Permintaan }\end{array}$ & Tahun 2003 & Tahun 2004 & Peningkatan & \multicolumn{1}{|c|}{ Persen } \\
\hline SNI & 7718 & 12.283 & 4565 & $37 \%$ \\
Standar lain & 2735 & 4049 & 1314 & $32 \%$ \\
Jumlah & 10453 & 16335 & 5882 & $36 \%$ \\
\hline
\end{tabular}

Data pada tabel 2 menunjukan permintaan SNI ke perpustakaan pada tahun 2004 (awal pelaksanaan SNI on line) mengalami kenaikan yang sangat berarti dibanding tahun sebelumnya, yaitu naik 37\% dari tahun 2003. Hal ini berarti bahwa penyelenggaraan layanan $\mathrm{SNI}$ on line sama sekali tidak mengakibatkan penurunan jumlah permintaan masyarakat terhadap SNI, bahkan sebaliknya.

\section{PERMASALAHAN YANG DIHADAPI}

Selama tahun 2004 yang merupakan tahun pertama pelaksanaan $\mathrm{SNI}$ on line, ternyata banyak permasalahan atau keluhan masyarakat terhadap BSN yang pada intinya dapat dikelompokan menjadi tiga kelompok permasalahan sebagai berikut:

a. permasalahan yang terkait dengan lambatnya koneksi ke website BSN yang mengakibatkan pengguna harus menunggu lama untuk dapat memanfaatkan $\mathrm{SNI}$ on line.

b. permasalahan yang terkait dengan materi SNI yang dianggap sangat terbatas jumlahnya dan tidak lengkap seperti pada indeks (6565 buah). Hal ini terkait dengan kebijakan BSN yang hanya menyajikan SNI terbaru hasil penetapan satu tahun terakhir. Kemampuan BSN menetapkan SNI setiap tahun berkisar antara 300-400 SNI

c. permasalahan yang terkait dengan kesulitan dalam download file SNI. Banyak pengguna yang tidak berhasil download file SNI fulltext yang kemungkinan akibat belum sempurnanya sistem penyajian SNI fulltext yang dilaksanakan BSN.

Ketiga permasalahan tersebut banyak disampaikan oleh masyarakat kepada BSN melalui forum layanan masyarakat yang sengaja disediakan pada website BSN. Mereka pada umumnya menghendaki adanya solusi tuntas terhadap masalah tersebut dalam waktu yang tidak terlalu lama.

\section{UPAYA TINDAK LANJUT}

Memperhatikan berbagai masukan tentang permasalahan yang dihadapi dalam pemanfaatan layanan SNI on line, beberapa hal yang perlu diupayakan untuk mengatasi permasalahan tersebut adalah:

a. meningkatkan kemampuan koneksi jaringan agar akses masyarakat dapat dilakukan lebih cepat dan tanpa batas waktu;

b. mengadakan evaluasi, uji coba dan penyempurnaan sistem penyajian $\mathrm{SNI}$ agar memberi kemudahan akses maupun kemudahan download file SNI fulltext bagi pengguna (user friendly);

c. mengadakan penyempurnaan format penyajian dan mencari kemungkinan mengadakan penambahan materi yang disajikan sehingga pengguna memperoleh lebih banyak pilihan materi dengan tampilan yang lebih menarik;

d. mengadakan sosialisasi secara intensif baik melalui media cetak maupun elektronik tentang SNI on line dengan menunjukan keunggulan maupun keterbatasannya agar masyarakat memperoleh informasi yang lengkap.

Upaya-upaya tersebut perlu segera dilakukan untuk membangun kepercayaan masyarakat terhadap BSN dalam penyebarluasan SNI.

\section{KESIMPULAN}

Penyelenggaraan layanan SNI on line pada website www.bsn.or.id telah mendapat respon positif dari masyarakat. Penyajian SNI on line ternyata juga tidak menurunkan jumlah permintaan SNI di perpustakaan, bahkan sebaliknya sangat leveraging terhadap permintaan standar. Hal ini menunjukan bahwa $\mathrm{SNI}$ on line telah mampu mendorong minat masyarakat untuk mencari dan mendapatkan informasi yang lebih luas tentang SNI. Namun demikian pada pelaksanaannya ternyata masih banyak hambatan terutama menyangkut 
lambatnya koneksi ke website bsn.or.id, kesulitan download SNI fulltext, dan terbatasnya materi SNI on line yang ada di website BSN. Keseluruhan permasalahan tersebut perlu penanganan BSN dalam waktu dekat. Implikasi dari hasil analisis adalah bahwa kebijakan BSN untuk menyelenggarakan layanan $\mathrm{SNI}$ on line perlu terus dilanjutkan karena ternyata SNI on line tidak hanya mampu menyediakan kemudahan akses terhadap SNI melainkan juga mampu mendorong minat masyarakat untuk mengetahui SNI secara lebih luas, yang berarti pula mendorong masyarakat menggunakan SNI.

\section{DAFTAR PUSTAKA}

1. Badan Standardisasi Nasional. 2000. Standardisasi Dalam Perspektif IImu, Industri dan Perdagangan. Jakarta: BSN.

2. Instruksi Presiden Republik Indonesia Nomor 3 tahun 2003 tentang Kebijakan dan Strategi Nasional Pengembangan EGovernment.
3. International Organisation for Standardisation. 1996. ISO Guide 2. Standardisation and related activitiesGeneral vocabularies. ISO.

4. Peraturan Pemerintah Republik Indonesia Nomor 102 tahun 2000 tentang Standardisasi Nasional.

5. Pusat Informasi dan Dokumentasi Standardisasi-BSN. 2005. Laporan Tahunan 2004. Jakarta: Pusido-BSN.

6. www.bsn.or.id . SNI Fulltext.

\section{BIODATA}

Tisyo Haryono, dilahirkan di Sumedang pada tanggal 12 Februari 1953. Penulis menyelesaikan Pasca Sarjana jurusan Library and Information Science di University of Pittsburgh USA. Saat ini penulis menjabat sebagai Kepala Pusat Informasi dan Dokumentasi, Badan Standardisasi Nasional. 